\title{
UN CAMBIO DE PARADIGMA: DE LA UNIVERSIDAD ESTATAL NACIONAL Y PÚBLICA A LA UNIVERSIDAD DE MERCADO $^{1}$
}

\section{A CHANGE OF PARADIGM: FROM THE STATE, NATIONAL AND PUBLIC UNIVERSITY TO THE MARKET UNIVERSITY}

\author{
Prof. Luis A. Riveros \\ Ex Rector Universidad de Chile \\ Facultad de Economía y Negocios \\ Universidad de Chile \\ Diagonal Paraguay 257 Of. 2201 \\ Santiago - Chile \\ lriveros@fen.uchile.cl
}

Resumen: Este trabajo discute las tareas que son responsabilidad de la universidad tradicional, especialmente en lo que toca a constituirse en depositaria de la memoria social y ser una conciencia crítica de la sociedad, a través de su reflexión y propuesta en la creación de nuevo conocimiento. Fue emblemática la Universidad estatal, nacional y pública que caracterizó el desarrollo de la educación en Latinoamérica durante el siglo XX, como entidad destinada a dialogar con su medio social, aportando al desarrollo, constituyéndose en depositaria del conocimiento y la cultura. Nuevas tareas se exigen a la universidad de hoy: contribuir a la innovación y al desarrollo de nuevo conocimiento o investigación aplicada y de adelanto; también, frente a las crecientes demandas por más universidad, se le pide ser una formadora de profesionales y posgraduados del mejor nivel. Pero, además, se le exige también hacerse cargo de su propio financiamiento por medio de venta de servicios. Como pone en evidencia el caso chileno descrito en este trabajo, el excesivo énfasis en las políticas de autofinanciamiento y la invasiva aplicación de políticas de mercado, han determinado que la universidad transite desde su rol social crítico, autónomo, nacional y público, hacia la venta privada de servicios destinada a sustentar su desenvolvimiento.

Palabras clave: Universidad; Autofinanciamiento; Pública; Formación; Conocimiento

Abstract: The tasks for which the traditional university is responsible -specially in becoming the trustee to the social memory and in being the critical conscience of society by means of its reflection and its 
proposals for the creation of new knowledge-are discussed in this paper. Emblematic was the state, national and public University that characterized the development of education in Latin America during the 20th century as an entity destined to dialog with its social surroundings, contributing to the expansion of new knowledge or applied investigation or progress. Also, due to the growing demands for more university, it is asked to form professionals and postgraduates of the highest level. But, in addition, it is required to assume its own financing by selling services. As it is evident in the Chilean case described in this paper, the excessive emphasis on the policy of selffinancing and the invasive application of market policies, have determined the university to traverse from its critical, autonomous, national and public social role towards the private sale of services to sustain its work.

Key words: University; Self-financing; Public; To Form; Knowledge.

Esto es lo grave: cada vez son menos los intelectuales que cumplen lealmente su oficio de pensar las cosas y hacérnoslas ver para preparar en nosotros la acción justa, adecuada, racional. Cuando pudiéramos pedirles a ellos un pensamiento de los problemas, los vemos correr como el más menesteroso de ideas, tras de las consignas y ofrecernos en lugar de verdades, decálogos. Y cuando esperamos que nos ayuden a liberarnos mediante el uso de la inteligencia crítica, les vemos ayudar al demagogo en su tarea de esclavizarnos en la adoración de sus fetiches. (Ortega y Gasset, 1927). 


\section{INTRODUCCIÓN}

La universidad en los días que corren parece ser concebida sólo como una fábrica de profesionales. En efecto, lo que prima en la mentalidad del hombre y la mujer medios de nuestra sociedad, es la idea de que la universidad está hecha sólo para preparar ingenieros, médicos, abogados, etc., y así conciben su misión permanente y casi exclusiva. De allí entonces que se entienda que una Universidad, para ser tal, requiere solamente de una planta física, ya que posiblemente lo que ocurra dentro de sus instalaciones sea solamente la enseñanza brindada por quienes han sido elegidos de algún modo para ello. Por desgracia, esto no dista mucho de la visión que tienen acerca de la universidad nuestros políticos, quienes deberían estar preparados para tomar decisiones trascendentales sobre el camino y futuro de la Universidad como una institución relacionada con el bien común. En el marco de las estrategias nacionales de desarrollo, ellos deben elaborar las bases de su misión y visión, para así establecer los distintos roles y espacios que la Universidad debe ocupar en su entorno social, y determinar el óptimo uso de recursos sociales para ese fin. Sin embargo, han dejado las políticas públicas de ser diseñadas sobre una base conceptual más amplia con respecto a la vieja institución universitaria, nacida por allá por el medioevo europeo con múltiples y trascendentes tareas, y que ha sobrevivido cambios de época muy vitales. No se trata de un culto al pasado y de una mecánica mantención de la misma noción de universidad tradicional y de su misión; se trata de rescatar su esencia, el fundamento de su rol en la sociedad del siglo XXI, con plena vigencia en los días de cambio que nos afectan.

Las universidades transitan en todo el mundo por tiempos notablemente paradójicos (Van Ginkel, 2011), en medio de muy grandes expectativas acerca de su posible contribución al hacer social en todos los campos del desarrollo humano y en las diversas perspectivas derivadas de su rol como institución social. Se demanda de la Universidad respuestas sobre asuntos y problemáticas antes impensadas, pero que resultan de las actuales tribulaciones de una sociedad en tránsito. Se requiere una Universidad pública que sea un espacio de integración social, a la vez que uno donde se formen las nuevas generaciones de académicos; se le pide que produzca conocimiento básico y aplicado para el desarrollo nacional, a la vez que sea un centro de innovación sobre prácticas docentes y de investigación. Al mismo tiempo, los cambios requeridos por parte de la Universidad envuelven presiones presupuestarias derivadas de aquellos otros cambios que están 
teniendo lugar en materia de finanzas del Estado, y se plantea la necesidad del autofinanciamiento del hacer universitario en sus distintas expresiones. Se espera también que la Universidad contribuya a la innovación, y del mismo modo colabore a fortalecer la competitividad que desafía a nuestras sociedades actuales, mientras al mismo tiempo ha de centrarse en la preparación de más y más cuadros profesionales y técnicos con una visión de futuro y de país.

En el contexto de las variadas y crecientes demandas sobre el hacer universitario, y en el marco de las más estrechas disponibilidades financieras que la misma sociedad está prodigando, se contribuye también a empequeñecer su rol, a limitar en forma severa su tarea en la perspectiva social, llevándola a desempeñarse en un plano material mayormente inclinado a un utilitarismo en boga en todos los aspectos de la llamada modernidad. En este sentido, la visión de la sociedad en cuanto al desarrollo de la Universidad se ha ido focalizando más y más hacia la entrega de resultados inmediatos y sobre todo a la atención formativa de las nuevas generaciones. Se trata de una universidad proveedora de servicios, una universidad de masas alejada sustantivamente de su antecesora selectiva, crítica y aportante de diagnósticos e ideas para el progreso social. Como en esos aspectos más concretos es que han tendido a concentrarse las políticas financieras hacia la Universidad, junto a un creciente desapego del Estado en cuanto a interesarse efectivamente en su desarrollo: Poco espacio parece quedar para la Universidad crítica que aporta con su reflexión al mejor hacer social, junto con la formación y la investigación y su innegablemente trascendente aporte a la cultura, al humanismo y al cultivo de las artes y las humanidades. Todo eso queda en niveles muy generales, atenidos a la disponibilidad de financiamiento y sometido a una gestión que debe estar más preocupada por responder a la inmediatez que inunda a la sociedad actual.

En este trabajo se examina la idea de universidad en términos de su rol social y como depositaria de la memoria social y cultural de una sociedad. Se plantean también las nuevas exigencias que se hacen a la universidad en los días presentes, y que muchas veces contradicen la esencia de la universidad tradicional y de su rol. Se examina el caso de Chile como un ejemplo extremo en cómo las políticas de desregulación y de mercado han amenazado las bases mismas de la tarea universitaria tradicional, para convertirlas más bien en una proveedora de servicios. 


\section{LA IDEA DE UNIVERSIDAD}

\section{Una amplia misión en pos de una sociedad en progreso}

La universidad se haya destinada a ser el ámbito protector y el campo experimental aún vivos de la esperanza humana...En ella mejor que en ningún otro medio, podemos ensayar las formas superiores de la libertad que el mundo de hoy tan dramáticamente necesita. (Jorge Millas, 1981). En esta afirmación se envuelve una idea trascendental de Universidad: protectora de la cultura, auspiciadora del desarrollo humano en su concepto más amplio, laboratorio de las formas superiores de la libertad. De aquí se derivan conceptos que han sido aplicados en diversos contextos a la idea de Universidad desde prácticamente sus orígenes: institución que almacena y desarrolla las formas culturales más diversas, proyecta ideas como un laboratorio social destinado a elaborarlas, y se hace responsable por la transferencia desarrollo y preservación del conocimiento. Eso es, ni más ni menos, lo que trasunta el famoso discurso de don Andrés Bello declarando la inauguración de la Universidad de Chile en 1842: una institución donde todas las verdades se tocan. Esa es la idea que subyace a la creación de la Universidad del Estado, como un gran ente pensante sobre la sociedad y su futuro, en que el descubrimiento científico se transforma en un instrumento para el progreso en las ideas y las formas de vida. A mediados del siglo XIX el concepto de universidad se inspira en la idea esencial de protección de la cultura, auspicio del desarrollo humano y laboratorio de la libertad; un gran centro de debate, propuesta y formación. Y, como es natural en un período en que se incuba la República, esta tarea se adscribe al Estado como el verdadero protector de la tarea universitaria.

El discurso de Bello hacía además alusión a la Universidad que debía prestar servicio a la Nación, más allá de un marco estrecho de tareas académicas, y que debía disponerse a siempre innovar para ir adaptándose a los cambios en su entorno. Argumentaba en su discurso inaugural: No se trata de aquellos establecimientos escolásticos o de ciencias especulativas, destinados principalmente a fomentar la vanidad de quienes desean un título aparente de suficiencia, sin ventajas reales o inmediatas para la sociedad actual. Se desea satisfacer, en primer lugar, una de las necesidades que más se han hecho sentir desde que con nuestra emancipación política pudimos abrir la puerta a los conocimientos útiles, echando las bases de un plan general que abrace estos conocimientos, en cuanto alcancen nuestras circunstancias, para 
prolongarlos con fruto en todo país y conservar y adelantar su enseñanza de un modo fijo y sistemático que permite, sin embargo, la adopción progresiva de los nuevos métodos y de los sucesivos adelantos que hagan las ciencias. Estos principios son aun plenamente vigentes en el contexto de modernidad y cambio que vive la Universidad en el mundo (Bello, 1842).

La tarea de la Universidad es eminentemente social, puesto que al centro de su tarea y misión está la preservación y creación del conocimiento que se manifiesta en progreso social, que aborda una cuestión que es problema de la sociedad toda. Y al decir social se resalta la esencia humanista de la Universidad, puesto que en lo social prima el ser humano como fin de todas las cosas, y no sólo como un medio para alcanzarlas. Por eso la Universidad ha sobrevivido muchos cambios de época, porque la memoria social radica en ella y porque desde ella aflora el proceso intelectual que genera el nuevo conocimiento y proyecta las nuevas formas sociales y la cultura hacia su futuro. Por eso también, la universidad debe ser un centro en que predomine la libertad de ideas y de expresión, porque no hay otra forma de crear lo nuevo sino con la objetividad de la inteligencia, ni de proyectar lo nuevo hacia el futuro sino sopesando con ecuanimidad el transcurso social. En palabras de don Andrés Bello La Universidad, señores, no sería digna de ocupar un lugar en nuestras instituciones sociales si (como murmuran algunos ecos oscuros de declamaciones antiguas) el cultivo de las ciencias y de las letras pudiera mirarse como peligroso bajo el punto de vista de nuestra moral o bajo el punto de vista político (Bello, 1842).

Por ello los ánimos interventores de la Universidad han siempre finalmente fracasado, y terminado en un remedo de institución académica, puesto que es la sobrevivencia misma del hacer social la que está en juego. Por eso Millas (1976) acotaba. La universidad vigilada no es, en efecto, superior a la Universidad comprometida... La Universidad, si ha de ser tal (y por cierto ella puede sobrevivir institucionalmente como un simulacro) sólo admite un compromiso: servir a la Nación por medio de la ciencia, en todos los sentidos. No hay manera de someter por la fuerza a la inteligencia ni establecer controles sobre las ideas, por más prohibiciones que se hagan. Muchos regímenes han bregado contra las Universidades como es el caso de los experimentos socialistas, las dictaduras fascistas o los regímenes inspirados en los dogmas religiosos; siempre la Universidad se ha antepuesto al control y la persecución, aunque en el corto plazo ellos hayan sido efectivos para doblegar el hacer académico. En el largo plazo 
se ha impuesto siempre la necesidad de una inteligencia desarrollada para buscar respuestas a las incógnitas levantadas por el futuro y la necesidad de contar con nuevo conocimiento para respaldar las exigencias del desarrollo.

La Universidad que se consolida en nuestro continente a partir del siglo XIX se fundamente en una idea de tarea nacional enmarcada en los siguientes principios: (1) Sostener y desarrollar la base intelectual de la sociedad, para su futuro desarrollo y crecimiento; (2) Promover el desarrollo humano ayudando a preservar la identidad cultural de la sociedad; (3) Otorgar inspiración y justificado orgullo a los ciudadanos en logro a través del tiempo de su propia sociedad; (4) Promover el diálogo y el entendimiento para apreciar y respetar la diversidad cultural y así también fomentar la integración social. Esto está también en la línea de lo señalado por van Ginkel (2011) con respecto a la Universidad europea. A esto, naturalmente, debe agregarse la misión de la Universidad en cuanto generadora de conocimiento, formadora de nuevas generaciones de profesionales, académicos e intelectuales y entidad preocupada de concebir y concretar su propia modernidad a través de la innovación. En este conjunto de ideas reside el concepto social de universidad, como un organismo pensante que aporta al progreso, impulsa las ideas, crea y disemina conocimiento para el progreso de la sociedad.

Lo más esencial de la institución universitaria es el conocimiento, manifestado en la mayor esencia científica de su dominio, aun cuando su misión sea postulada en forma más amplia: la protección y proyección de la cultura. Y es que la Universidad debe ser un centro de ideas y debate, un permanente proceso de búsqueda de la verdad, no como un fenómeno inamovible y dogmático, sino como una fórmula para transitar permanentemente por el camino de la reflexión y la interpretación de los fenómenos. Y es por ello que la Universidad necesita diversidad y tolerancia, puesto que la existencia de muchas distintas ideas, junto a una actitud siempre abierta a recibirlas y posiblemente a combatirlas, debe ser parte inherente a la creación de nuevo conocimiento y al proceso de generación de una memoria social y de una cultura representativa de las formas dinámicas y diversas que adquiera el mundo. La creación y cultivo del conocimiento y de la búsqueda, el rechazo a las normas que pueden intentar coartar su libertad académica y su autonomía institucional, son temas hoy y siempre en debate, en donde siempre ha triunfado una visión de Universidad en la línea de su larga historia y de su consecuente legado. 


\section{La investigación científica}

Si la esfera del nuevo conocimiento es un campo propio de la universidad, entonces lo es la investigación científica como asimismo el amplio campo de la creación. Sin embargo, es también equivocado creer que la universidad debe ser un organismo dedicado enteramente a la investigación científica, constituyendo ésta la esencia exclusiva de su hacer. Como Millas (1985) postuló: En buenas cuentas, la ciencia no hace a la universidad, y si tratara de hacerla, la destruiría; pero la universidad vive de ella, y sin ella perece. La investigación científica es un hacer fundamental en la universidad, puesto que sin ella no hay manera real de hacer efectiva la creación de nuevo conocimiento. Pero es también fundamental comprender que la tarea universitaria va mucho más allá, y como depositaria de la cultura que es, necesita que el conocimiento científico estricto se combine adecuadamente con el conocimiento social y la creación en artes y humanidades. Esto es, la universidad debe ser completa y compleja si es que ha de cumplir en forma satisfactoria con su misión fundamental en la sociedad. La ciencia es la dignidad de la universidad; más aún-porque al fin y al cabo hay quien vive sin dignidad - es el alma de la Universidad, el principio mismo que le nutre de vida e impide que sea sólo un vil mecanismo, (Millas, 1981).

En respaldo de esa universidad compleja que es sinónimo de la verdadera universidad, Ortega y Gasset (1992) sostuvo que La universidad es distinta pero inseparable de la ciencia ... la universidad es además ciencias...tiene que vivir de ella... la ciencia es el alma de la universidad...la tiene que intervenir como tal universidad, tratando los grandes temas del día desde su punto de vista propio -cultural, profesional o científico. Este principio de ciencia inherente a la universidad, pero no excluyente de su más amplio rol social llevó a de Luxan (1998) a concluir que el paradigma universitario se presenta por tanto indisolublemente unido a demandas culturales, de formación profesional y de creación de conocimiento, en un ambiente de excelencia académica y científica.

Si la ciencia, y por tanto la investigación científica, es central a la universidad, es menester también destacar que su docencia en el contexto de una universidad con campos delimitados en cuanto a su tarea formadora hace de la investigación científica universitaria algo limitado y carente de una proyección en todo su potencial. La investigación se 
puede también, como de hecho siempre ha ocurrido, llevar a cabo en empresas privadas o en instituciones de investigación no universitarias. Pero esto impone una severa limitación en la calidad y pertenencia de la investigación y de sus resultados, puesto que las ideas no son nunca contrastadas con otras visiones de ciencia ni apoyadas en otros ámbitos científicos pertinentes en la búsqueda de respuestas relevantes. No hay, por ejemplo, una ciencia social que ordene las preguntas y califique la utilidad de las respuestas, ni hay otras ciencias duras que permitan proyectar los hallazgos a partir de la ciencia básica y hacia sus aplicaciones en las disciplinas tecnológicas. Es decir, aunque la investigación focalizada en productos y resultados sea útil en el sentido aplicado con que se la concibe, ella es mucho menos relevante y sus respuestas menos potentes que aquellas generadas en un ambiente de controversia con distintos campos del conocimiento. Por eso, la investigación universitaria es en muchos sentidos superior a los hallazgos puntuales y usualmente sujetos a retos de productividad y ganancias que se produce en el contexto de la empresa, y definitivamente superior a la investigación científica que se lleva a cabo en forma aislada de la visión humanista.

El siglo XXI está ahondando en algunas demandas sobre la universidad estatal y pública. Por una parte, enfatizando la necesidad de crear conocimiento nuevo para el desarrollo del país o región, que es concebida como una tarea inexcusable de la institución universitaria. En segundo lugar, ser un efectivo centro que integre distintos grupos sociales y económicos, que sea una muestra representativa de la sociedad para liderar del punto de vista de las ideas, el diálogo social y el encuentro permanente de un país. Asimismo, debe ser la universidad la formadora de profesionales, académicos e intelectuales para permitir el crecimiento del sistema y la profundización de su trabajo. Al mismo tiempo, debe ser un centro activo de innovación de nuevas ideas y de progreso en lo intelectual, lo moral y lo productivo. Tareas todas no menores, donde se debe preservar el espíritu de bien público que debe envolver el hacer universitario, muchas veces tan contradictorio con el incentivo privado que se ha tratado de fortalecer por las políticas de financiamiento.

\section{EL ROL SOCIAL DE LA UNIVERSIDAD}


La universidad necesita un contacto cada vez más activo con el medio social y sus respectivas audiencias. Porque, sin ser una entidad perteneciente al dominio de los servicios sociales, no puede dejar de ser un referente como parte de la sociedad que es, y cumpliendo un rol esencial en torno a la protección y desarrollo de valores esenciales para el futuro de la sociedad. Por eso la labor de extensión o de relación con el medio, término éste mucho más apropiado a la esencia de la labor universitaria, es un componente esencial que hoy en día es más y más exigido. La universidad no es una torre de cristal como argumentaban los estudiantes en pro de la reforma postulada en los años sesenta, ya que desde la esfera social debían venir las problemáticas y preguntas a resolver y en aquella debían vaciarse las respuestas provistas por el cuerpo universitario. Sobre esta materia poca duda cabe. Sin embargo, el principal problema se refiere a cómo tiene lugar esta interacción Universidad- sociedad, en base a qué medios y en qué medida la demanda social es mandante, determinante exclusiva, del hacer de la universidad. Es decir, la pregunta es en qué medida la demanda social ha de ser considerada una importante restricción a la libertad académica y la autonomía universitaria. Sobre esto último, es crucial considerar que los requerimientos sociales actúan como un factor orientador determinante del hacer universitario, tanto por la vía de los recursos, como asimismo de la realidad política que se crea en torno al papel de la universidad. La cuestión fundamental radica en que la libertad académica debe ser capaz de proyectar otras ideas adicionales, generar nuevas iniciativas, elaborar sobre la base de otros principios orientadores que no sean solamente aquellos surgidos de la exposición social contingente. Y la autonomía universitaria no excluye el mandato social, la aspiración de la sociedad a que ciertas respuestas sean provistas, además detonadas las otras que la universidad crea pertinente en el libre ejercicio de su rol.

En Córdoba, Argentina, en 1918, luego de un largo período de vida de la Universidad Republicana se produjo el primer conflicto universitario significativo en América Latina, el cual levantó un agudo cuestionamiento al rol de la universidad en la sociedad. Este conflicto derivó de la incorporación de nuevos grupos sociales a la vida política y universitaria, y de la entrada definitiva de la sociedad a la modernidad. Desde allí en adelante la universidad se entendió como parte de la modernización de las sociedades y participante activa en este proceso, ligando hacer universitario y problemática social de una manera explícita. Las ideas subyacentes sobre sociedad y universidad siguieron ejerciendo un papel crucial en el diseño de la política universitaria en 
todo el continente, y respaldando los siguientes movimientos de reforma que notarían más que ahondar en la extensión y profundidad de ese compromiso social adquirido por la universidad.

En tiempos de la reforma universitaria impulsada en los años sesenta se postuló que la universidad era la conciencia crítica social. Por cierto, este postulado guardaba relación con los objetivos políticos del proceso, y la necesidad que había, de acuerdo a sus impulsores, de construir un bastión intelectual que propugnara el cambio social por la vía de la crítica a las estructuras y modos de producción vigentes. Pero más allá, y en un sentido profundo, la universidad siempre ha sido una conciencia de la sociedad. Por una parte, porque la universidad es depositaria de una cierta memoria social, donde radica la cultura, el conocimiento, el hacer social e histórico en su concepto más amplio. Es la universidad el intelecto seleccionado que actúa como una conciencia almacenando lo importante, lo más indeleble y permitiendo que exista un base estable para el cambio social. Pero al mismo tiempo, la universidad no puede ser concebida sólo como un archivo gigantesco que guarda todo lo relevante del hacer social. La universidad genera nuevas ideas, y responde al cuerpo social que, a su vez, levanta demandas sobre formas posibles de cambio para mejorar la condición humana. La creación y el conocimiento son el aporte esencial de la universidad hacia la vida social, conjugándose con las nuevas generaciones que son formadas en sus aulas y destinadas a aportar al progreso social en sus distintas formas y facetas.

Según Ferro (1996) la universidad tiene dos responsabilidades manifiestas en dos campos bien delimitados: desarrollo de la ciencia y la tecnología, y promoción de proyectos de desarrollo social, incluyendo cultura. Pero no debe perderse de vista que ambas esferas envuelven un rol social marcado que hacen de la universidad una entidad relevante en ese plano, y como lo es también en cuanto centro de reflexión y propuesta social, desde su sitial independiente, educando a nuevas generaciones para que cumplan así también sus responsabilidades con la sociedad. Por eso también se ha reseñado con énfasis, que el retorno privado del trabajo universitario puede ser comparativamente pequeño respecto del uso de los recursos en otras acciones financieras, pero que el retorno social es significativo en la medida en que la universidad impacta positivamente en aspectos no directamente medibles, pero claramente relevantes en la actividad social. 


\section{EL CAMBIO PRESENTE EN LAS DEMANDAS HACIA LA UNIVERSIDAD}

\section{Las nuevas exigencias sociales}

Como se ha dicho más arriba, en los días presentes a la Universidad se le demanda una multiplicidad de tareas en consonancia con los tiempos de globalización y de información generalizada que prevalecen. Por ejemplo, se le exige contribuir a la innovación y a la mayor competitividad que se espera impere en la sociedad moderna. Asimismo, se demanda de la universidad una enseñanza actualizada y efectiva, para que los jóvenes que acceden a ella puedan ver rubricados sus esfuerzos con ingresos adecuados. Además, se le exige una alta cobertura, de modo que no existan segmentos sociales y de ningún orden que queden sistemáticamente fuera de los estudios universitarios.

De esa manera la sociedad le exige a la universidad ser completamente abierta, discriminar en la menor medida posible y casi sin establecer normas académicas rígidas que puedan ser interpretadas como una barrera social o de otro tipo. Se le exige también a la universidad de hoy en día, ser la fuente de conocimiento nuevo, objetivo y preparado para sus aplicaciones en todos los campos en beneficio del ciudadano común, especialmente en ciencia y tecnología. Se le plantea la necesidad de ser un observatorio social, un centro de debate de ideas, una especie de testigo independiente del tránsito social y de sus muchas exigencias de cambio, y sea al mismo tiempo un actor relevante en términos de producir integración social. Se establece la noción de que la universidad cobije a las artes y a las humanidades, como manifestaciones superiores del intelecto humano, pero también como aspectos que van siendo dejados de lado en medio del frío tránsito social y económico dominado por el consumismo y el materialismo y que en forma consonante a su importancia deben ser protegidos. Unida a esta ya larga lista de demandas, se le plantea también a la universidad el autofinanciarse, basándose en su propio hacer, para así también proveer docencia e investigación de calidad que debe brindarse a la sociedad toda. Finalmente, también se exige a la universidad el ser internacionalizada, esto es mantener los mejores vínculos hacia el exterior, integrarse con otras universidades relevantes en lo posible, y enviar a estudiantes y profesores a otras aulas y recibir los extranjeros, como una manera de conservar y mejorar los estándares académicos. Por supuesto, y sin tener una noción específica en lo que ello significa, se le 
exige a la universidad que su tarea se desempeña con pertinencia y calidad.

El notable conjunto de viejas y nuevas demandas que se ejercen sobre las universidades a nivel planetario poco dependen del estatus económico o del tipo de organización política de los países. Hay una mundialización en curso que afecta sobremanera las expectativas sobre el rol de la universidad que edifica cada sociedad. En medio de la sociedad globalizada empiezan a imperar las comparaciones sobre la efectividad en el cumplimiento de las tareas, aún radicadas en aspectos formales o presumiblemente centrales al hacer de las universidades, como las publicaciones y citaciones científicas o las distinciones de sus académicos y egresados, o la relevancia y visibilidad de sus páginas web. Pero, los nuevos requerimientos no son claramente especificados en cuanto al grado de alcance que podrían tener comparativamente, del modo como los otros son considerados en los actuales rankings mundiales o regionales de universidades. El énfasis que se otorga a las distintas demandas específicas es variable, pero ciertamente el contenido general de ellas es muy vigente y está impulsando, en concepto de Van Ginkel (2011), un cambio copernicano con relación a la tarea y la organización universitarias. Las universidades deben hoy en día competir para captar sus estudiantes, realizar investigación en alianzas relevantes y conseguir financiamiento apropiado para todo ello. Eso aparte de proteger la cultura el arte y las normas de vida de la buena sociedad, además de liderar la innovación y la competitividad. No eran, claramente, éstas las tareas de la universidad durante la mayor parte de su historia, incluyendo la mayor parte del siglo XX, especialmente en los estados de bienestar europeos, en Canadá, la mayor parte de Asia y casi toda Latinoamérica, caracterizados por un gran desarrollo de la universidad pública compleja y selectiva.

\section{La Universidad de masas}

Fue Ortega y Gasset en 1930, quien al identificar la misión de la universidad con la formación general del hombre medio se adelantó a la realidad que hoy nos domina: la universidad de masas. Al calificar de masas a la universidad, se hace referencia a la profunda transformación que supone, en un período relativamente corto, de una o dos generaciones, el incremento exponencial del número de alumnos (de Luxan, 1998). Es, en efecto, el fenómeno global presente en nuestros días, y que los políticos señalan con tanto orgullo, consiste en la enorme expansión de la universidad en materia de cobertura o de matrícula, 
haciéndola efectivamente un fenómeno masivo. Las posibilidades de superar la crisis de crecimiento del sistema universitario aparecen encorsetadas tras un tratamiento uniformador, que concibe por igual las características de todas las instituciones universitarias, que esencialmente trata por igual demandas y apoyos distintos, y que se procesan en un sistema complejo compuesto por organizaciones que pese a contar con un perfil diferenciado y en buena medida contradictorio, reciben desde el sistema político un mensaje sustancialmente idéntico (de Luxan, 1998). Este diagnóstico aplicado al caso español es precisamente una demostración de lo global que es el fenómeno de expansión de la universidad y de los motivos políticos tras ello.

El nuevo tipo de universidad que se está perfilando en el mundo se liga a factores culturales nuevos y a fenómenos abiertamente de mercado. Esos fenómenos, a su vez, se vinculan con la mundialización o globalización, que desafía la estructura de valores o principios que caracterizaron a las sociedades más encerradas en sí mismas vigentes durante buena parte de la historia de la universidad como institución. Hoy, el desafío de la universidad tiene que ver con la interpretación y proyección de esas mezclas culturales que surgen de la mundialización en curso, como también con la protección de la cultura que está siendo invadida, y en muchos casos desplazada, por la incidencia del fenómeno global. Pero más allá de eso, la universidad está inmersa hoy día en la economía-mundo, la welwirtschaft a que aludió el historiador francés Ferdinand Braudel: una universidad que compite globalmente y que se identifica con la idea de lograr mayores ventas, mayor calidad académica, para así también edificar su política comunicacional. Se le exige producir conocimiento útil derivado de las ciencias, pero la universidad debe rechazar esto puesto que la ciencia tiene responsabilidades con la humanidad que sobrepasan los límites del pragmatismo y la comprometen con la generación de conocimiento que aumenten la capacidad crítica de nuestros análisis de la sociedad y de nosotros mismos, que nos den la posibilidad de entender las dimensiones menos pragmáticas, pero, no por eso menos relevantes e ineludibles de la civilización que estamos construyendo, de la calidad de vida que estamos buscando, de la dignidad humana y de los valores de la vida del hombre, que podemos dejar de buscar o cuya construcción histórica tendremos la oportunidad de asumir, para que nuestro aporte universitario a la cultura signifique una visión de largo plazo en la que sean el hombre y la mujer, cultos y autónomos, los objetivos de nuestro proyecto educativo del siglo XXI, (Ferro, 1996). 


\section{Los nuevos retos en materia de financiamiento}

$\mathrm{Si}$ en su pasado de origen la universidad fue una entidad ampliamente sustentada en la beneficencia y la existencia de sustantivos mecenazgos, en los tiempos modernos ella fue una hija predilecta del Estado de Bienestar. No hay aquí solamente un abierto intento de dar acceso a todos a la formación de capital humano altamente calificado sobre la base de los recursos del Estado, que en gran medida fue la ambición alentada por los países europeos y un intento seriamente perseguido por los países latinoamericanos. Primó más bien la noción de que hay tareas de la universidad que no son sino bienes públicos y constituyen externalidades que deben ser financiadas por la sociedad toda a través de los recursos públicos. En los EE. UU. por ejemplo, se origina desde temprano está clara división entre el producto universitario que conduce a rentabilidad privada, es decir es apropiable privadamente como los ingresos del ejercicio profesional derivado de la formación obtenida en la universidad o el patentamiento de investigación destinada a ser distribuída a través del mercado, de aquél otro que tiene que ver con productos universitarios que conforman puro rédito social. En este último acápite pertenece la investigación más pura, al menos aquella que ejerce rentabilidad social por sus efectos directos e indirectos, a través de derivaciones en otros productos aplicables y el desarrollo de capacidad de generar conocimiento de base para nueva futura investigación. También está aquí la entrega de la posibilidad de formarse en la universidad a aquellos que no están en condiciones económicas de acceder a ella, aunque sí lo están del punto de vista intelectual. Por cierto, que esta distinción entre el beneficio privado y beneficio social deja espacio a muchas situaciones de claro - oscuro, que ameritan cuidadosa discusión y agudas discusiones en materia de asignaciones de recursos a las universidades.

También se ha pensado que puede distinguirse entre la universidad pública y la universidad privada en términos del énfasis de sus productos y de las asociadas necesidades de financiamiento público o privado. Ha sido, sin embargo, un intento poco satisfactorio. Es difícil intentar encasillar a una universidad en función del tipo de productos que debe privilegiar, más aún cuando la universidad debe estar dotada de plena autonomía para definir el carácter y ámbito de sus acciones en cuanto a docencia, investigación y vinculación con el medio. Por eso, los subsidios que entrega el Estado en forma directa son objeto de continuo análisis y debate, puesto que se alega que mucho de esos recursos se destinan a financiar bienes privados y no aquellos por los 
cuales debiera velar la sociedad como un interés propio. Incluso en bienes que son de connotación eminentemente pública, hay componentes privados que son inevitablemente subsidiados por el Estado, aunque ellos constituyan una forma de otorgar recursos a una élite; es el caso del financiamiento que se otorga a las artes, cuyo beneficio es público mayoritariamente pero también se subsidia por esta vías conciertos para las élites o muestras de pintura o arte escénico orientadas a sectores sociales acomodados.

Los subsidios entregados a la educación universitaria durante el siglo pasado para hacerla gratuita, fue eminentemente regresiva, ya que con recursos de todos los ciudadanos se ofrecía universidad gratis a los hijos de la élite económica y social, quienes habrían estado en condiciones de financiar lo que sería posteriormente su capital privado. Indudablemente que dentro de esa misma política tuvo cabida la oportunidad para muchos jóvenes que no habrían estado de otra manera en condiciones de financiar su acceso a la universidad. ¿Quién o cómo podría haberse distinguido este grupo de necesidad frente al más generalizado caso de regresividad? También es importante señalar que no todo aquello que muchos obtuvieron en materia de su formación profesional gracias a los subsidios del Estado, fue puramente un recurso que produjo un retorno privado. El ejercicio de las muchas profesiones, la obligación de entregar un tiempo de servicio al Estado o a sectores de reconocida falencia económica y social, lograba transformar mucho del rédito privado en un rédito social. El contexto de privatización del ejercicio profesional, entregado a puros mecanismos de mercado, eliminó esta posibilidad de devolución que seguía la tradición universitaria instalada desde tiempos fundacionales: a la universidad se ingresa para recibir y se egresa para entregar.

Todos los países han avanzado en la formulación de un sistema de financiación mixto, que envuelve importantes subsidios del Estado y una no menor contribución del sector privado por la vía de las donaciones como a través del pago directo de los servicios universitarios, incluyendo por cierto la formación de pre y posgrado. Incluso en países europeos y latinoamericanos, antaño centrados en la financiación pública, hoy se han abierto a permitir una sustancial participación del financiamiento privado. Tanto aquellos países con mayor extensión del campo de financiamiento privado, como son los EE. UU y Corea, y aquellos con una mayor incidencia estatal, México y España, por ejemplo, han avanzado hacia la adopción de sistemas con un aún mayor grado de participación privada en el presupuesto total de gastos de la educación 
superior. Aquí han primado las nuevas tendencias macroeconómicas que aconsejan reducir un a veces desmedido déficit público (generalmente, sin embargo, no derivado de un excesivo gasto en educación) y promueven un severo recorte en todo aquello que puede ser financiado privadamente en virtud de sus potenciales retornos privados. La salud, la previsión y la educación, en general, han caído en estas tendencias, aunque también se ha aceptado que a menor el nivel educativo mayor ha de ser el financiamiento público proporcionalmente hablando, puesto que así se maximizan las externalidad sociales para las que se dispone de esos presupuestos. La cuestión de fondo es que se ha avanzado hacia un sistema con mayor financiación privada y menor, y aún más decreciente, participación del sector público.

Lo anterior no implica, sin embargo, que sea el mercado el instrumento fundamental que oriente el desarrollo de la función universitaria y le prodigue el debido financiamiento. El mercado tiene un rol que jugar, considerando la diversidad pública y privada del producto universitario. Pero ello no puede dejar al sistema y a la formulación de sus haceres, como un simple resultado del dictamen del mercado; es aquí donde surge el tema de la regulación que requiere un sistema privado universitario, para mantener, sin lesionar la autonomía implícita en los proyectos educativos, un cierto debido respeto por el rol social de la universidad y sus tareas. Evidentemente, como lo indica la experiencia de muchas realidades, incluyendo USA, Canadá, Japón, Corea y Europa, las universidades estatales son el mejor parámetro para actuar como referente de calidad y en cuanto a la orientación y nivel del trabajo universitario.

Las universidades estatales han sufrido un estrechamiento en sus financiamientos porque las políticas privatistas, instauradas en distintas medidas en los diversos países, exigen de este modo que ellas se concentren en aquello que es irrenunciable y definitiva y exclusivamente público. El sector privado ha expandido también su oferta en la misma medida en que las nuevas políticas exigen una ampliación en la cobertura universitaria junto con una mayor participación del sector privado en la financiación de la actividad universitaria, especialmente la docencia. Esta expansión privada, en muchas partes, se ha hecho a costa de la calidad, puesto que lo priman son los precios y el no fácilmente identificable bien que se adquiere gracias a los estudios universitarios. De todo esto, las reformas implantadas en el modelo universitario chileno son un muy buen ejemplo. 
La financiación privada que se ha ido imponiendo crecientemente en el mundo como el mecanismo más viable para financiar a una universidad con costos cada vez más elevados, ha ido también afectando la autonomía de la universidad y la libertad académica. La financiación vía donaciones está intentando dirigir desde afuera el hacer universitario, un tema sobre el cual siempre existió discusión en los siglo XVIII y XIX, esto es la forma de asegurar que la universidad fuese capaz de elegir los temas pertinentes y desarrollarlos en pro de un beneficio social identificable. El dinero privado, que intenta maximizar la obtención de un beneficio identificable en términos de investigación, docencia o extensión, está modelando el tipo de universidad y la forma en que ella debe orientar su trabajo en los ámbitos que le correspondan... Aquí se abre un tema de corriente relevancia en términos de si acaso privilegiar más la autonomía y la libertad académica o la disponibilidad del recurso privado. Por cierto, en esto algo ha de tener que ejercer como responsabilidad el financiamiento estatal, que deberá ahora responder a otros patrones, distintos de aquellos del financiamiento fijo y sin rendición de cuentas ni observación de las condiciones de producción.

\section{Los cambios en las formas de organización}

Consecuente con las demandas que hoy día pesan sobre el sistema, las universidades han debido repensarse en sus formas de organización, sus métodos de gobierno y modos de operar, además de sus sistemas de relaciones exteriores. En muchos casos han cambiado también los criterios para la selección de los académicos, llevando este proceso hacia líneas menos puristas que aquellos vinculados estrictamente a la productividad académica de excelencia. Se encuentran muchas veces orientados, más bien, a la necesidad de atraer recursos financieros por la vía de los fondos de investigación y de apoyo a programas académicos de ciencia aplicada, a la perspectiva de patentar la creación universitaria o de tener mayor acceso a las donaciones privadas o a la beneficencia, que hoy han pasado a ser un factor crucial como elemento determinante del trabajo universitario.

En el caso de la universidad pública, dominada por su orientación hacia los temas nacionales y la investigación de beneficio común o con altas externalidades, como también con el desarrollo de estudios y formaciones menos rentables, pero si socialmente de alto interés, ella también se ha ido modelando de modo distinto como producto de las nuevas políticas financieras del Estado y la imposición de restricciones que, si bien es cierto violan la autonomía universitaria y la libertad 
académica, tienen alta acogida en el mundo político porque así se logra imponer una agenda de interés político al trabajo académico más trascendente. Hoy en día en las universidades públicas las vicerrectorías de finanzas o económicas han pasado a tener un rol preponderante no sólo en el manejo de las materias de su natural incumbencia, sino que han pasado a ser una virtual instancia resolutiva en toda materia académica.

En general, las universidades están siendo profundamente transformadas sobre la base de los requerimientos sociales y de las políticas públicas. Por esa razón empiezan a ser comunes también, como no lo eran antes, las vicerrectorías o instancias superiores en materia de investigación, las oficinas de patentamiento y gestión de proyectos con financiamiento externo, las oficinas de relación universidad-empresa, las instancias internas dedicadas a la mantención de estándares de calidad del trabajo académico y otras unidades de alto rango dedicadas al diseño y puesta en marcha del plan estratégico de desarrollo. Todo esto ha cambiado el perfil organizacional de la universidad, haciendo más complejo su organigrama y creando nuevas dificultades, especialmente en universidades que cultivan una política de participación, en cuanto a las relaciones entre las unidades centrales y las facultades y departamentos académicos.

Claramente, y, por otra parte, la sociedad no puede permitirse perder completamente un cierto control de la educación superior. No solo necesita los especialistas para ir edificando el futuro, sino también generar una elite intelectual para dar guía al desarrollo de la nación y de la humanidad como un todo (Van Ginkel 2011). Por ello, aunque se impongan nuevas formas de trabajo y organización de la universidad, la sociedad debe imponer formas de asegurar relevancia y pertinencia de su hacer, para lo cual surgen ya los métodos de acreditación, cuentas de gestión, evaluación de las políticas de acceso y provisión de recursos de investigación. Indudablemente que muchas veces existe abierta contradicción entre el uso de estos mecanismos y la existencia de una universidad libre y auto determinada, pero debe primar aquí la cuestión más esencial, cual es la respuesta que la sociedad busca de su ente pensante que es la Universidad., desde donde se espera surjan orientaciones que permitan construir una sociedad mejor, un progreso equilibrado, una noción adecuada de justicia social.

\section{EL CASO DE LA UNIVERSIDAD CHILENA PRE-DICTADURA}


Las universidades chilenas venían arrastrando problemas importantes desde mediados de los años sesenta, producto de los requerimientos que ejercían los sucesivos giros que experimentaba la sociedad. Por una parte, había una necesidad evidente de aumentar la cobertura del sistema, como resultado del crecimiento demográfico, el cambio en la estructura social y de la expansión que había adquirido la educación secundaria. Había, en efecto, una creciente demanda por cabida en la Universidad de parte de una clase media que se expandía rápidamente como resultado de una mayor población urbana y la existencia de una desarrollada labor del Estado de Bienestar. Movilidad social era uno de los objetivos primordiales de las políticas públicas que sustentaban el desarrollo de la educación, y la Universidad se veía precisamente como el hito más decisivo por medio del que los grupos medios podían acceder a una mejora sustentable de su status socioeconómico. Existía, asimismo, la necesidad de proveer una diversificación en los ámbitos disciplinarios y de formación profesional que proveía la universidad porque el aparato productivo y de servicios experimentaba también cambios importantes de la mano con un progresivo cambio tecnológico, que requería mayores y distintas especializaciones en muchos campos. La creación de nuevas carreras en campos disciplinarios diversos se llevaba a cabo conjuntamente con la apertura de Sedes universitarias en un gran número de ciudades, que respondían a una creciente demanda por formación profesional y que las universidades habían ido satisfaciendo primero con institutos o colegios regionales, que pasaron pronto a convertirse en sedes con formaciones profesionales equivalentes a las entregadas ya en las principales ciudades del país (Cifuentes, 1997).

La universidad chilena se había desarrollado al amparo de la estrategia de sustitución de importaciones que el país intentaba seguir desde fines de los años treinta. Este modelo envolvía un alto grado de participación del Estado en materias productivas y económicas en general, y se hacía acompañar por el intento de construir un Estado de Bienestar a-la-europea, con servicios sociales abiertos con amplio financiamiento público, servicios entre los que cabía la salud, la previsión y la educación. Por lo mismo, esto llevó a la universidad a estar al centro de una confrontación de intereses, siendo observada por muchos como parte de una arquitectura política definida, de un cierto modelo político que consideraba al Estado como el eje central promotor del desarrollo. En el contexto del modelo que siguieron los gobiernos chilenos a partir por lo menos de la década de 1930 se encontraba la idea de la educación como un instrumento de democratización social y 
política, creando así un amplio espectro de oportunidades y un espacio para reclamarlas. De hecho, como se ha destacado (Saavedra, 1999), si se toma a la población electoral como un indicador de las crecientes demandas por servicios del Estado, la misma alcanzó a $10 \%$ de la población nacional en 1930, y ya hacia 1957 alcanzaba a 17\%. En 1972 la proporción de población con derechos electorales creció a $45 \%$. Eso reflejaba adecuadamente el ritmo de expansión que adquirían las demandas que la sociedad iba imponiendo al trabajo universitario.

Desde mediados de los años sesenta, por otra parte, la sociedad chilena caminaba hacia una decisiva crisis social y política que era, ni más ni menos, que el reflejo de la guerra fría que ocurría a nivel global y que comprendía el enfrentamiento de dos visiones muy distintas de la realidad y sobre el necesario cambio social y económico que de acuerdo a tal diagnóstico se precisaba. Ello se manifestaba en una creciente contradicción entre los sectores que estaban por un cambio profundo y estructural en la línea del socialismo que se había edificado en los países de la órbita soviética y aquellos que estaban por mantener el statu quo en materia económica, social y política, no sin excluir de todo ello a aquellos sectores que aceptaban, desde el centro político, la necesidad de cambios moderados en estos aspectos. Chile había experimentado desde los tempranos años 1930 la sucesión de una serie de gobiernos que iban desde la centroizquierda a la centroderecha, pero sin proveer plena satisfacción a las demandas sociales más esenciales, que parecían ir siempre por delante de las realidades económicas, presupuestarias y de política pública. La cuestión económica se mantenía como un trasfondo de crucial relevancia en el ambiente de insatisfacción que mostraba la sociedad chilena, puesto que el país se veía crecientemente bajo la presión de un bajo crecimiento, un sostenido déficit fiscal y la existencia de un tasa de inflación cuyos mayores niveles, a comienzos de la década de 1970, pusieron en evidencia la existencia de una crisis con cruciales implicancias sociales y políticas.

Las universidades eran muy sensibles a estos temas, como centros de reflexión sobre la sociedad que ellas habían sido tradicionalmente, contando con la activa participación de los estudiantes que, en la composición de sus organizaciones, reflejaban las mismas opciones políticas y discusiones de fondo que aquellas prevalecientes en la sociedad en su conjunto. Se animaban en el plano interno profundas reformas institucionales en la línea de cogobierno estudiantil y en la aspiración a un mayor y más visible compromiso social de la universidad en la línea de los ánimos de cambio que invadían todos los terrenos del 
quehacer social. Por ello se proponía transformar la estructura de la cátedra tradicional para así favorecer la incorporación de nuevos elementos académicos que fueran portadores activos de este mensaje de cambio extensivo. Se proponía también que los claustros abiertos fueran el modo de conducir las decisiones académicas más trascendentales, eliminando de golpe los cuerpos de gobierno basados en la tradición universitaria y en la jerarquía académica. Así las cosas, las universidades se encontraban convulsionadas y en una época de trascendental debate acerca de los profundos cambios que se planteaban con relación a su hacer, su estructura y su misión en la sociedad chilena. El tema del compromiso político requerido por parte de la universidad, en medio de la gran confrontación partidaria que vivía Chile, hizo susceptible a la universidad de una gran injerencia ideológica en sus decisiones y modos de organización, junto al reclamo por mayor compromiso frente al giro social, económico y político que las fuerzas más progresistas ambicionaban para Chile.

\section{INTERVENCIÓN Y DESARTICULACIÓN DE LA UNIVERSIDAD: 1973 - 1979}

La intervención de las universidades chilenas a partir de septiembre de 1973 fue drástica y tuvo lugar a través de dos mecanismos fundamentales. Primero, por medio de una abierta intervención política a través de rectores delegados, en un principio todos ellos oficiales activos de las distintas ramas militares, y un sistema de nominación directa de las autoridades correspondientes a los diversos organismos académicos. Todo esto ocurría junto con la eliminación de los organismos colegiados de gobierno que tenían vida en la universidad, y con una sistemática depuración política que, bajo diferentes expedientes, alcanzó a funcionarios, académicos y estudiantes, quienes fueron simplemente expulsados, los que no habían sido encarcelados o se encontraban desaparecidos o en el exilio. Segundo, tuvo lugar un significativo recorte presupuestario para todo el sistema a partir de 1974, en línea con el esfuerzo de estabilización que se llevó a cabo a partir de 1975 junto con un proceso de reducción del tamaño y gasto del Estado Across-the-. board. Esta situación impidió que la universidad chilena se pudiera repensar en forma adecuada para que se pudiese enfrentar la nueva situación de Chile y el mundo en el campo político, económico, social, tecnológico y productivo; la universidad debió volcarse a atender sus asuntos presupuestarios y de financiamiento, al básico reordenamiento de su trabajo en el nuevo escenario político e institucional. No hubo oportunidad, y del punto de vista de muchos de 
los actores involucrados no hubo tampoco intención, para que el cuerpo universitario entrara en los temas académicos u organizacionales de fondo que necesitaba enfrentar por medio de una discusión amplia centrada en el interés institucional. La universidad fue simplemente vista como un aspecto el todo social y político que necesitaba abordarse y controlarse en pro de los objetivos centrales del gobierno militar.

Fueron años de retroceso y estancamiento, que profundizaron la crisis originada a fines de los años 1960 y que la universidad en verdad no había resuelto, y abrían el camino a soluciones aún más detrimentales para su ya herido ethos institucional. La universidad chilena necesitaba debatir acerca de su rol en la sociedad, y acerca de los cambios en estructuras y formas de gobierno que deberían tener lugar para cumplir con las nuevas tareas. Muchos universitarios -decía Jorge Millaspodemos evocar esta situación en el paso y reconocerla con rasgos detestables en el presente: el estado de alienación de nuestras universidades. Alienación llamamos en general al traspaso de una cosa a poder ajeno; de una manera más específica a la centrifugación de su ser espiritual cuyo discernimiento y voluntad ya no le pertenecen, por haberlo entregado o haberle sido arrebatado con la consiguiente pérdida de identidad y autonomía. Una universidad cautiva fue la sucesora de esa universidad de enfrentamiento y politización. Esta etapa de intervención y desarticulación de la universidad tendría efectos posteriores de muy largo plazo, esencialmente perjudiciales para la libertad de cátedra y de investigación.

Entre 1967 y 1973 el crecimiento anual de la matrícula universitaria fue de $16.6 \%$, cifra que se redujo a un magro $1.7 \%$ entre 1973 y 1979. Pero no sólo eso: las universidades estatales contrajeron su matrícula a un ritmo de $3.4 \%$ anual en este período, dejando por cierto al sistema sin capacidad de cobertura a pesar de la demanda que se hacía evidente. Todo esto se subsanaría más tarde con el aparecimiento y expansión del sistema privado en la década de los ochenta. Para ello, un primer paso fue el nuevo texto constitucional de 1980, que establecía la libertad de enseñanza como un principio orientador de la nueva política educacional, pero a través de un concepto limitado al derecho a abrir, organizar y mantener establecimientos educacionales; es decir, como una expresión más de la libertad de empresa dominante bajo las nuevas políticas económicas. De la libertad para enseñar y para poder ejercer visiones distintas en la construcción del conocimiento no hubo nada que tradujera una mínima comprensión sobre la tarea de la universidad. 
Durante las dos décadas anteriores al retorno a la democracia se incubaron serios problemas que afectaron la calidad y equidad del sistema de educación chileno que posteriormente no se han corregido. Todo esto fue resultado de la puesta en práctica de un extremo ideologismo de derecha: el mercado todo lo soluciona, el Estado siempre lo hace de peor forma que el sector privado. Así como abundó el ideologismo de izquierda en el período de fines de los años 60 e inicios de los 70, se impuso un ideologismo mucho más pernicioso que simplemente destruyó a la educación chilena.

Los cambios de fondo comenzaron a perfilarse precisamente en ese año 1979. Una directiva Presidencial de 1979 dirigida al Ministerio de Educación establecía que:

(a) El gobierno se reservaba toda la tuición sobre los contenidos de la enseñanza;

(b) se restringía la responsabilidad social del Estado en el terreno educacional, implicando que los estudiantes y sus familias debían hacerse cargo de los costos que ella irrogare;

(c) se limitaba la acción directa del Estado y se abría un amplio espacio para la participación directa del sector privado y de los gobiernos locales como proveedores de educación;

(d) tendría lugar un esfuerzo especial de privatización del segmento de la educación técnico profesional a través del traspaso de la misma a la empresa privada;

(e) en las universidades se impondría una política de autofinanciamiento, en virtud de lo cual las acciones de la universidad quedaban sujetas a los recursos que, más allá del mínimo aporte estatal que recibían para investigación básica, se podrían obtener para tareas de extensión o investigación aplicada.

El Decreto de 1979 formalizaba algunas cuestiones que constituían de hecho la manera en como habían venido funcionando desde 1973. Como se hacía además necesario que el gobierno pusiera nuevas normas de organización y funcionamiento que prevalecerían en las universidades chilenas, que hasta entonces no habían sido sometidas a cambios institucionales de fondo, el Decreto Ley 3541 de 1980 le entregó atribuciones al Presidente de la República para que en el plazo de un año procediera a reestructurar las universidades del país, incluida la Universidad de Chile.

\section{LA ADOPCIÓN DE UNA VISIÓN MERCANTILISTA: 1980-1990}


Los años del Gobierno Militar fueron duros para la Universidad de Chile, como asimismo para el resto del sistema, especialmente la otra universidad estatal y nacional: la Universidad Técnica del Estado (UTE). No sólo porque se persiguieron ideas, se coartó la libertad académica y se hizo añicos el principios de la autonomía institucional en la toma de decisiones, todos elementos básicos para desarrollar relevancia y excelencia académica, sino también porque se produjo el cambio drástico en las reglas que tradicionalmente habían regulado el sistema de educación superior. Hacia la segunda parte del gobierno militar, en la década de 1980, se redefinieron las líneas tradicionales del trabajo universitario, se entró a una nueva realidad dominada por lo que más tarde se evidenciarían también como tendencias globales: autofinanciamiento, segmentación del sistema universitario y de investigación, predominio de la universidad-empresa, relegación de la universidad nacional y pública. Durante la primera etapa, esto es en la década de 1970, las políticas del gobierno militar estuvieron inspiradas en la idea de aplacar las manifestaciones del ambiente político que reinaba en la universidad chilena a partir del período de la reforma, y en la percepción que se tenía sobre el uso de recursos abundantes en materia universitaria ( $\sin$ olvidar que el financiamiento casi total del gasto universitario a comienzos de los setenta provenía de recursos estatales directos) sin que se entendiera claramente, por parte del régimen militar, la importancia que tenía esta función, aparte, ciertamente, de la de formar profesionales en las diversas disciplinas.

\section{El desarrollo de las universidades privadas}

Un primer fundamental cambio ocurrido a comienzos de los años 1980 fue que el gobierno militar permitió la creación y desarrollo de universidades privadas sin generar junto a ello normativas que impusieran una adecuada regulación ni establecieran condiciones para lograr adecuados estándares de calidad. Sin más, en pocos años, se había fundado un número significativo de estas instituciones que, de ese modo, competían con las universidades tradicionales (que a poco andar crecieron de 8 a 25 con la presencia de universidades derivadas) y hacían del terreno de la docencia uno donde campeaba una cultura de supermercado: elegir al mejor y más conveniente proveedor basado en 
costos y en las bondades declaradas del producto ofrecido. Así se desarrollaron escuelas de todos los ámbitos profesionales, y el país se hizo de grandes inversiones nacionales y extranjeras en este campo, mientras que el aparato fiscalizador estuvo prácticamente ausente, en la expectativa de que el propio sistema generaría información para que sobrevivieran los mejores oferentes. El tiempo mostró con crudeza que este simplista supuesto no fue necesariamente el caso, ya que la información en un mercado tan complejo como el de la educación superior, que en realidad lleva a cabo transacciones de futuros, era imperfecta y llevaba a que no se corrigiesen automáticamente los defectos de calidad de instituciones privadas y públicas.

Es importante destacar que la autorización para el funcionamiento autónomo de las nuevas corporaciones universitarias tenía lugar a través de un recientemente creado Consejo Superior de Educación. Dos sistemas se pusieron en práctica para que este organismo pudiera otorgar la autonomía a las instituciones: un sistema de examinación, que era llevado a cabo por universidades tradicionales, es decir ya constituidas en calidad de tales, y un sistema de acreditación que conducía el propio Consejo Superior de Educación. Entonces, es menester reconocer que el surgimiento del nuevo sistema estuvo, al menos en parte, asociada al rol de las propias instituciones tradicionales a cargo de los procesos de examinación conducentes a la autonomía. Naturalmente, el proceso a cargo de estas universidades envolvía una remuneración que para muchas instituciones resultó ser un atractivo incentivo para llevar a cabo esa tarea de enorme significancia. Pero no sólo esto fue parte del problema asociado al surgimiento de las nuevas universidades; el problema era que, una vez obtenida la autonomía con una o dos carreras, las universidades así declaradas autónomas podían crear todo tipo de carreras y crecer de un modo incontrolable. Varias universidades obtuvieron su autonomía con, por ejemplo, carreras de Derecho e Ingeniería Comercial, pero una vez autónomas crearon carreras de Medicina, Ingeniería, Odontología y de cuanta especialidad pareció pertinente a los objetivos de crecimiento y financiación.

El ex Director de Educación Superior Raúl Allard, puso de manifiesto que hasta 1999 existía un total de 22 instituciones privadas que habían logrado plena su autonomía por diferentes vías, incluyendo ocho universidades. Y agregaba... lo que les permite crear nuevos programas sin requerir autorización, lo que es un signo de la progresiva consolidación del sistema (Allard, 2000). Esto señala como, del punto de vista del gobierno se veía como una gran ventaja la existencia de una 
liberalidad total en el desarrollo del sistema universitario, una materia en que otros creían debía prevalecer mucho más estudio y restricciones para evitar un crecimiento inadecuado de carreras y programas.

En 1990 existían ya 60 universidades, de las cuales 35 eran privadas originadas en los últimos 8 años con la vigencia de la nueva ley. Aunque la gran mayoría de estas instituciones no eran autónomas a esa fecha, tenían un actuar muy visible en la oferta educativa disponible. Era esta una situación distinta al escenario previo (fines de los 1960s) en que existían sólo 8 instituciones ( 2 estatales y 6 privadas con financiamiento estatal) todas ellas regidas por un amplio conjunto de regulaciones y normas específicas. La Universidad de Chile a partir de este profundo cambio, debió moverse en un campo de creciente competencia, pero, sobre todo, de una invasiva visión comercial y de marketing que contrastaba con lo que otrora había sido el campo de la academia y la razón más pura. Se daba así un paso decisivo en materia de cobertura del sistema de educación superior, que había sido una de las presiones manifiestas ya en la década de 1960, y que daba satisfacción a una gran aspiración de la sociedad chilena.

\section{Gráfico 1.}

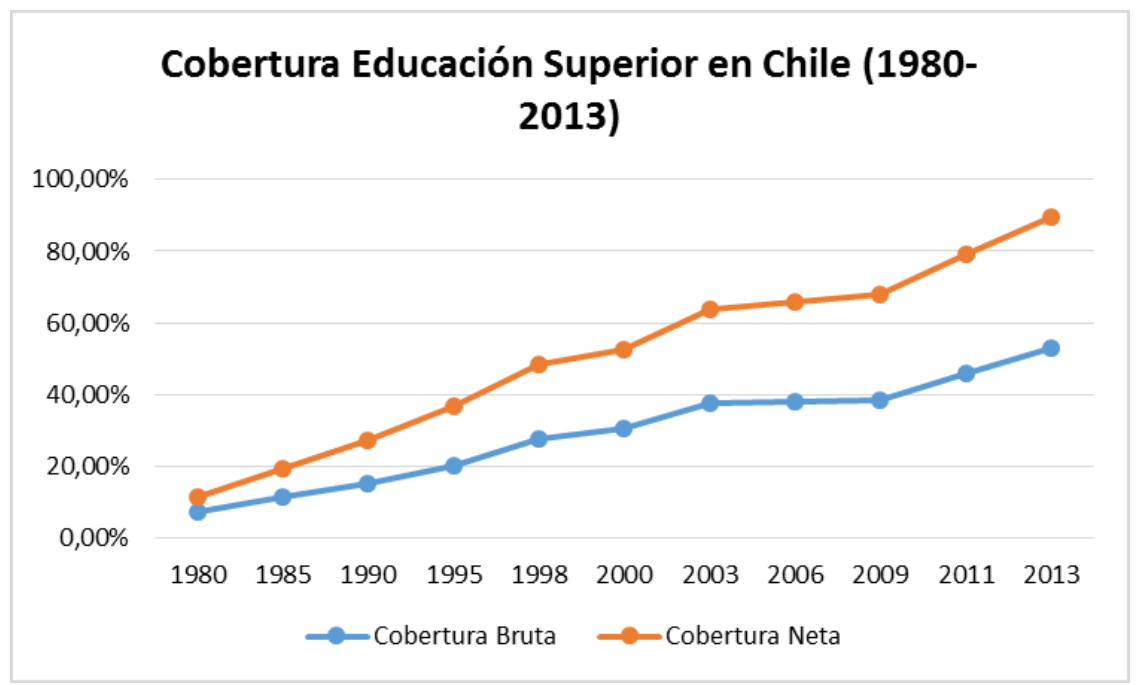

Se hacía merced la oportunidad de desarrollar universidades como iniciativa privada, muchas de las cuales se desarrollarían en forma ostensible para llegar a convertirse, dos o tres décadas más tarde, en instituciones con mayor cuerpo, aunque todas ellas, ciertamente, concentradas en tareas puramente docentes. 
El nuevo sistema privado, vista la portentosa inversión en infraestructura y difusión que le ha caracterizado a lo largo del tiempo, parece haber sido altamente rentable, especialmente porque los precios fueron completamente libres, fijados sólo en función de la demanda aspiracional de parte de los diversos grupos sociales, que encontraron cada cual una universidad para su propia realidad económica y social. También abundaron las universidades de congregaciones religiosas y de grupos políticos de distinta índole, con lo cual el sistema parece haberse blindado en cuanto a su desarrollo futuro en la seguridad de una diversidad propietaria que cruzaba todos los espectros políticos y valóricos.

\section{UN CAMBIO CRUCIAL EN EL SISTEMA DE FINANCIACIÓN DE LAS UNIVERSIDADES TRADICIONALES}

Un segundo campo de reforma ocurrida en la década de 1980 consistió en imponer una nueva cultura presupuestaria en las universidades: habría un Aporte Directo (AFD) para todas las entidades tradicionales o pertenecientes al Consejo de Rectores de Universidades Chilenas (CRUCH) junto con un Aporte Indirecto (AFI) otorgado a las instituciones en función de los 27000 mejores puntajes de la prueba de selección para el ingreso a la universidad. Además, podrían las universidades concursar por recursos adicionales para investigación y creación a través del sistema CONICYT en las líneas FONDECYT o de otros proyectos asociados al fondo de Desarrollo Institucional o a recursos del Consejo Nacional para la Innovación y la Competitividad. Los primeros ítems (AFD + AFI) pondrían a la Universidad de Chile en el plano actual (2016) de ser financiada por el Estado (su propietario) en alrededor de un $14 \%$ de su gasto total (cifra en todo caso declinante año a año), mientras que se elevaba un tanto por sobre un $30 \%$ en total considerando todos los recursos estatales directos o concursables a los que podía acceder la Universidad de Chile. El restante $70 \%$ se debía lograr en base a los aranceles estudiantiles y la venta de servicios que obligaba a la universidad a cobrar por todo, bajo el principio de recuperación de costos. Este nuevo escenario resultaba en extremo 
contraste con la realidad anterior al golpe militar, en que la Universidad de Chile recibía aproximadamente un $92 \%$ de su presupuesto desde el Estado central. El pago de aranceles, por otro lado, cambió la situación de una universidad prácticamente sin costos para el estudiante, a una que requería un pago no poco significativo (y que años más tarde se ha reconocido como uno de los más altos del mundo), transformado en gran aliciente para la inversión privada y demandante de un sistema de becas y crédito que fueron ejerciendo significativa presión sobre el sistema y la política pública.

\section{La normativa respecto al campo específico de las carreras universitarias}

En tercer lugar, la reforma de 1981, implementada a través del Decreto con Fuerza de Ley $\mathrm{N}^{\mathrm{o}}$ 4, permitió al gobierno fijar la normativa universitaria en materias más específicas. La universidad fue definida como una institución de educación superior de investigación, raciocinio y cultura (sic) que debía atender las necesidades del país al más alto nivel de excelencia. Así, se determinó administrativamente cuáles carreras o formaciones profesionales eran de carácter universitario y cuáles no, esto es las que habían de proveer una licenciatura, para así distinguirlas de otras carreras en el sistema de educación superior que no podrían hacerlo. En esta línea se determinó en un principio que la formación de profesores no debía recaer en las universidades, cosa que después se modificó con el mismo juicio administrativo con que una barbaridad como esa se había adoptado. La idea tras esta iniciativa era dejar un campo de formación técnica predefinido, para un conjunto de nuevas instituciones que se habían creado (Institutos Profesionales y Centros de Formación Técnica) las cuales no podrían proveer una licenciatura, pero cuyos campos de trabajo nunca fueron precisados. En verdad nunca se definió más tarde que era uno u otro tipo de institución y cuál era el grado de compromiso del Estado y de la política pública con esta formación tan importante para el desarrollo del país, y en qué medida las mismas formaban parte de un sistema con cierta coordinación. Todavía, treinta años más tarde, predomina una clara indefinición a este respecto.

\section{La reducción de los recursos para la educación}

La disminución de los aportes estatales para la educación, en general, fue muy significativa, cayendo de más de 6\% del PIB en 1970, a un porcentaje de $2.36 \%$ al año 1990 . Se reflejaba así una errónea visión 
del gobierno militar, inducida por los economistas que respaldaron su desempeño, en que la educación debía ser vista no como un bien público, sino más bien como un bien de consumo al que podrían tener acceso las familias de acuerdo a su disposición a pagar. El mercado resolvería la situación, mientras que la educación pública debía dejarse como la alternativa para quienes no accedieran al sistema privado. Se llevó a cabo con esto una extensiva privatización de la educación a todo nivel, definiendo el Estado un sistema de subvención o subsidio para los proveedores privados de educación preescolar, básica y media, sujeto a normas muy superficiales en cuanto al cumplimiento de su tarea, que era así delegada por el Estado. En el caso general, el otorgamiento de este subsidio no se hizo restrictivo en función del lucro que podría estar asociado a las empresas gestoras de la educación, ya que éste fue un problema solamente establecido para el campo universitario. En el caso de las universidades, el apoyo estatal que incluía los aportes directo e indirecto, además de las ayudas estudiantiles y el financiamiento de fondos concursables, se empinaba en poco sobre 0.3\% del PIB en 1990. Veinte años más tarde, en 2010, el aporte a toda la educación alcanzaba sólo a 4.2\% del PIB, y el financiamiento universitario (ahora mayoritariamente consistente en ayudas estudiantiles) era poco más de $0.7 \%$ del PIB, manteniendo la sostenida herencia de los cambios de 1981 .

\section{Financiamiento y diseño político de la educación pública}

Todos estos cambios en la forma de funcionar de la educación superior y de financiarse, ahora con un significativamente mayor componente privado, se daban en el marco de una política pública orientada a la reducción del tamaño del Estado chileno, a una minimización de su rol orientador, ejecutor de acciones de producción y regulador en materia de desarrollo sectorial y nacional. Se entregaba a mecanismos de mercado la asignación de los recursos, incluyendo educación, salud y previsión social, en un marco de liberalización económica y amplia privatización, junto a una apertura comercial y financiera que el país edificó con gran énfasis desde mediados de la década de 1970. En el marco de estas definiciones globales de política, como se comprenderá, el plano de la educación era uno más de un conjunto de sectores que debía también estar dominado por liberalización, reducción del Estado, autofinanciamiento y plena competencia. Sin más, se llevó el tema general económico a la educación considerando que ésta era una industria más del conjunto nacional. 


\section{LA CONTINUIDAD DE LAS POLÍTICAS DE LOS OCHENTA EN LOS AÑOS NOVENTA}

Muchos se preguntan la razón porqué la Concertación de Partidos por la Democracia habría adoptado una política que favoreció la continuidad de aquellas diseñadas en los años ochenta con relación a la educación superior, su privatización y el asociado desmantelamiento de las universidades públicas. En realidad, parece ser que aquí jugaron tres factores esenciales. Por una parte, el hecho definitivamente ineludible de que el aumento de cobertura del sistema de educación superior (no sólo universitario) requería un activo y creciente rol del sector privado. Ello, indudablemente, contaba con el progresivo proceso de depuración que habría de seguir al juego de las reglas del mercado, sin considerar que el mismo proceso induciría pérdidas enormes a las personas que se identificaban con la formación obtenida en una institución más tarde cuestionada o desaparecida. No hubo, en realidad, una discusión sobre las implicancias de la política de total liberalidad que se gestó en los ochenta y se alentó con el retorno a la democracia. El aumento en la cobertura se veía como un impecable objetivo político a lograr, que era incuestionablemente apreciado por la ciudadanía, y que, en definitiva, y en una economía con creciente ingreso per cápita, no crearía sino mayores ambiciones y demandas que sostendrían la expansión del sistema privado. El problema es que eso se hizo a costa de las universidades públicas, de los bienes públicos que ellas eran supuestas de producir y teniendo como contrapartida un evidente deterioro en la calidad del hacer universitario en docencia y también un decaimiento en materia de investigación, toda vez que ese no fue un producto exigible al nuevo y expansivo sector privado.

Una segunda razón para la política de dejar hacer que llevó a cabo la Concertación fue la inspiración de un acuerdo programático no explícito, pero sí muy activamente ejecutado. Se dijo que la atención preferencial de las políticas públicas durante el primer período de la Concertación sería la educación básica, a la que efectivamente se le allegaron recursos, se le proporcionó inversión y se indujo una política de cobertura efectiva lograda también con el apoyo de bienes complementarios al estrictamente escolar. Sin ninguna duda, con esto se privilegió un objetivo de equidad que resulta evidentemente importante, especialmente cuando la cobertura escolar es un objetivo que cumple otros complementarios, pero de igual trascendencia social. Se dijo, además, que el segundo período de la Concertación sería el de la Educación Media, cuando efectivamente también se llevaron cabo 
reformas que condujeron a mayor inversión y un mayor gasto en presupuesto de funcionamiento. Ninguna de estas iniciativas, que efectivamente condujeron a un aumento importante (o recuperación, deberíamos decir) del gasto público en educación, tomó en cuenta la transversalidad del problema: que mejor educación era importante y que ello requería un esfuerzo en cuanto a formación de profesores, lo cual requería atender también prioridades del sistema de educación superior. Tampoco se visualizó que la expansión y consolidación de la educación básica y media del país aumentaría los requerimientos por educación superior, que iba, en el curso de esos ocho primero años de Concertación, afirmándose en muy discutibles líneas de calidad y equidad. Esa particular estrategia también dejó de lado el hecho que se permitía así el deterioro progresivo y sostenido de una educación superior en crisis de financiamiento, así como también de calidad y equidad, y que eso tendría un costo político irreparable, como de hecho así parece haber sido. El tercer período de la Concertación abordó algunos temas importantes en materia de educación superior, como el ordenamiento del financiamiento estudiantil y la creación de un sistema de acreditación de calidad. Pero ya el sistema estaba asentado como se había venido desarrollando. Se temió que el cambio de reglas del juego afectara fatalmente al sector privado, o mucho de él, y las políticas no se animaron a la reforma universitaria que se necesitaba, requiriendo una nueva definición acerca del rol y financiamiento de la Universidad pública, un sistema de regulación armonioso y sustentable de la actividad de la educación superior, y una corrección de los parámetros de extrema libertad que habían caracterizado el desarrollo del sistema privado y habían permitido, a la vez, el decaimiento de la educación pública universitaria.

El tercer factor que permitió la continuidad de las políticas creadas en la década de los años ochenta fue el rol activo de los Ideologismos, por una parte, y de los tecnócratas por otra. El ideologismo, voluntarioso y poco renovado, exigía volver a la realidad de los años sesenta, posiblemente eliminando al nuevo sector privado, reconstituyendo las grandes universidades nacionales y recreando un sistema inviable por la capacidad de absorber el porcentaje de población joven que ya estaba adherida al nuevo sistema. El nuevo sistema, por otro lado, ya existía de hecho: había nuevas universidades con cinco o más años de vida, existían ya generaciones de profesionales formados en ellas, y se advertía un dinámico proceso de inversión en el campo de nuevas universidades, el cual había logrado prominencia en las vísperas del proceso de tránsito a la democracia. El alegato ideológico, que se alejaba de lo que estaba ocurriendo en todo el mundo, no se centró en los 
aspectos fundamentales y necesarios de corregir del nuevo sistema que se asentaba. Por su propia inviabilidad como postulado de ideas, esta línea de pensamiento permitió la continuidad. Los tecnócratas, por otra parte, constituyó una pléyade de personajes que adquirieron la condición de expertos en educación, especialmente en educación superior, en la mayoría de los casos merced a su audacia como también a su ligazón con el nuevo sector privado que se instalaba y crecía en el país, y que por cierto lo estimulaba y en buena medida lo auspiciaba. Sin ser académicos de trayectoria, reconocidos por sus pares ni vinculados a la tradicionalidad de la universidad chilena, estos expertos recomendaron a todos quienes quisieron escucharlos, que el sistema desarrollado en los años ochenta era la nueva tendencia que había que respetar y continuar. Asumían que ese era el aggiornamiento que necesitaba la educación chilena y que era, por lo demás, concordante con el espíritu de la política macroeconómica, con la idea de que lo privado era siempre más efectivo y eficiente que lo público, y que había que dejar que el mercado entregara su veredicto respecto del futuro del sistema a través del futuro de sus egresados.

Las protestas estudiantiles de 2006 y 2011 pondrían de relieve los problemas que ha generado esta política de inacción, o de acción insuficiente frente a los problemas de la educación, especialmente de la educación superior. Ha hecho crisis el problema de inequidad asociado al modelo simplista de cada uno paga por lo que puede obtener; ha hecho crisis la municipalización de la educación, la falta de innovación, la inadecuada formación de profesores, el inadaptado sistema de financiamiento de la educación pública, la falta de regulación adecuada sobre la educación privada, la crisis de la investigación en cuanto a su financiamiento y su organización, etc. Ha hecho crisis la cuestión de la calidad del sistema universitario, concepto difícil de definir pero que puede al menos ser aproximado por los años de acreditación que en la actualidad muestra un muy débil logro por parte del conjunto de universidades: 


\section{Gráfico 2.}

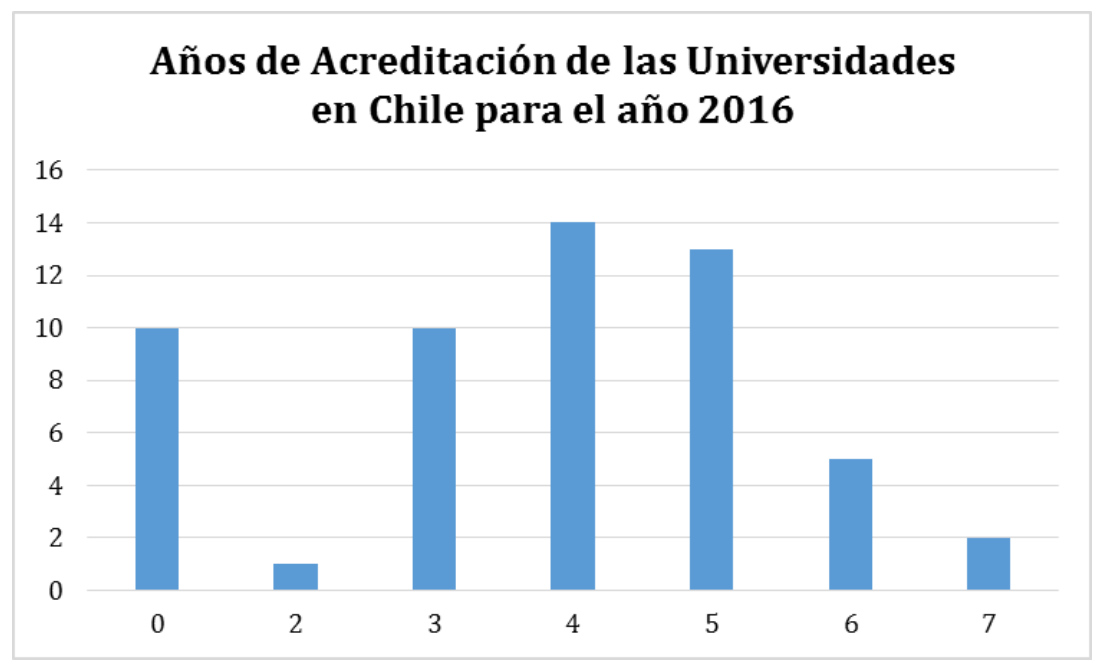

Gráfico 3.

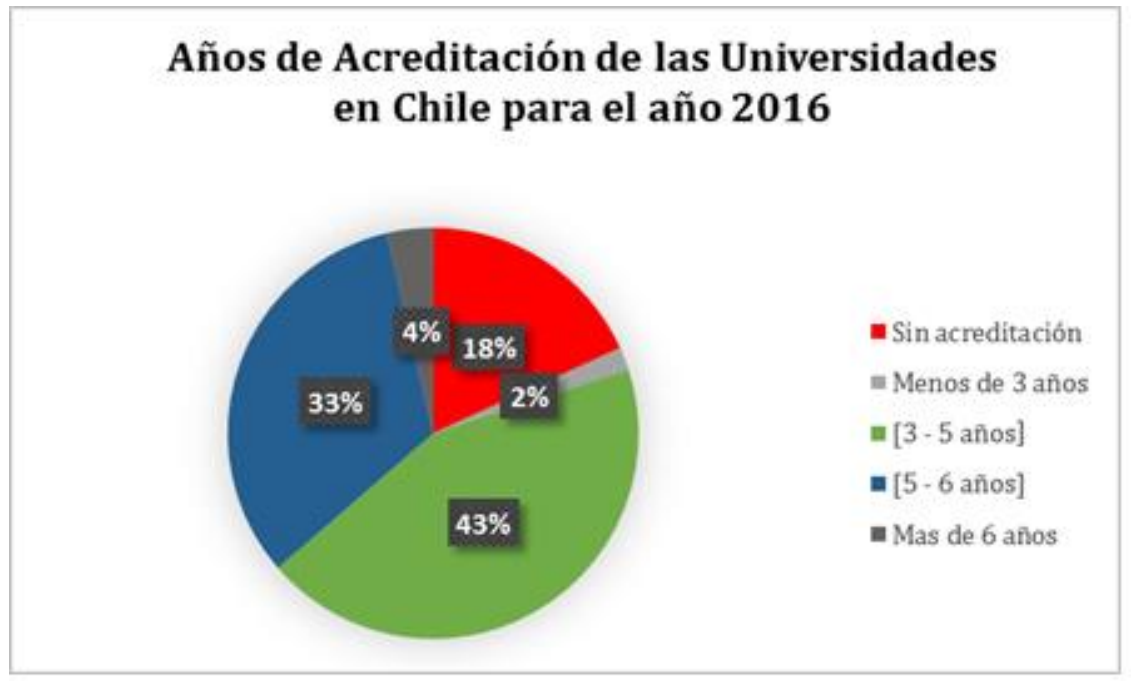

Por cierto, son estos problemas que afectan al desarrollo que el país ambiciona, pero que se siguen abordando con una mirada parcial, sin percibir la necesidad de una reforma modernizadora, no una evocadora de las glorias del pasado, que ponga a la educación superior chilena, y a su educación en general, en la línea de responder a las urgencias desatadas por la sociedad globalizada, de la información y del conocimiento, que nos ha invadido y de la cual no podremos ya escapar. 
La actual Administración (2016) ha enfrentado el problema de la educación superior con dos instrumentos principales. Primero, estableciendo la política de gratuidad universal para los estudiantes, partiendo con aquellos pertenecientes a los deciles de más bajos ingresos. Segundo, poniendo en práctica una política de restricciones mayores a las universidades privadas, especialmente en términos de prohibir el lucro y fijando los aranceles. No hay mayores cambios, sin embargo, con respecto al rol y financiamiento de la universidad pública, para cuyas tareas de investigación, extensión y relación con el medio, deberá seguir dependiendo de una más bien abierta.

\section{A MODO DE CONCLUSIÓN}

En medio de esta creciente oleada de modernización o actualización exigida a la universidad en el contexto de la globalización que presenciamos, nos alejamos a mucha distancia de esa universidad fábrica de profesionales que nos legó la experiencia del siglo XX. Hoy en día las tareas de la universidad son mayores y muy complejas y requieren una arquitectura distinta para proveer las respuestas que la sociedad espera. Se quiere una universidad que forme individuos críticos y conscientes de su responsabilidad social, además de estar compenetrados de las complejas dinámicas disciplinarias. Se ambiciona una institución capaz de generar nuevo conocimiento para el progreso y el logro de mejor calidad de vida y que también contribuya al acervo cultural y a la memoria social de un modo activo. Se requiere una institución capaz de reflexionar y postular con independencia ideas importantes para el progreso social y para la protección y desarrollo de la cultura. Pero, además, una institución que determine la relevancia de las preguntas a ser abordadas y las respuestas a ser elaboradas por medio de una activa relación con el medio social, ya que de esta manera cobrará vida la extensión universitaria (desde la universidad hacia el medio) y la integración de la problemática social hacia la universidad. Son todos estos roles complejos, y procesos que envuelven un cambio no exento de dificultades, impidiendo además que las universidades sean vistas como organismos uniformes, sometidas todas al mismo hacer en sus aspectos específicos. 
Los roles descritos anteriormente tienen distintas facetas y enfoques que ameritan una distinción entre las universidades. Por una parte, está la universidad nacional, pública por las necesidades inherentes a su tarea, y que tiene que ver con esos temas de país que deben abordarse desde una perspectiva de desarrollo académico tanto investigativo como formativo. Es la universidad que debe responder a preguntas que no están necesariamente en el mercado en un minuto del tiempo, puesto que obedecen a tareas que son necesidades de país, como lo es por ejemplo la investigación de adelanto, y sobre la cual Didriksson (2000) ha reseñado el conjunto de importantes desafíos que se enfrentan. Por otra parte, está la nueva universidad basada centralmente en incentivos privados que cumple un rol en cuanto a cubrir la expansión de la matrícula y a generar cierta limitada investigación, por lo general, que se acrecienta en la medida que la institución va madurando y logra desarrollar mayor inversión y atracción de recursos académicos. La experiencia de muchos países desarrollados se ubica en esta realidad, con una contribución significativa de ambas vertientes, pública y privada, con una interacción que contribuye a crear un espacio colaborativo y socialmente relevante.

La universidad está sufriendo un enorme tránsito en las materias que hemos descrito más arriba, y continuará sufriendo una drástica evolución en la misma medida en que el tránsito social y el proceso de globalización se vayan haciendo más complejos, más integradores y más activos en la forma de modelar la sociedad futura. Su función social, sin embargo, se ha enaltecido puesto que, ante lo impredecible del futuro, es importante que una institución esté destinada a almacenar los contenidos culturales y científicos, y también a buscar las nuevas respuestas ante las nuevas posibles preguntas. La labor de reflexión y propuesta de la universidad no debe considerarse superada como parte de su hacer. Es cada vez más fundamental, aunque sea mayormente desplazada de la visión política, las medidas de estado, la política pública y todo aquello que se pone a rendir pleitesía sólo a los objetivos más instrumentales y de corto plazo. La universidad debe validarse ante la sociedad y la ciudadanía, como la institución pensante, libre y tolerante que es y debe ser. Otra cosa no es sino remedo de universidad, aunque sea también formadora de profesionales y adscrita a ideas determinadas sobre su rol en la sociedad. La verdadera universidad crea nuevas ideas, pertenece al ethos de la transgresión sobre lo vigente, y se formula como una institución capaz de proyectar a la sociedad hacia los días futuros. 
Con mucha razón Gonzalo Villapalos (1998) ha dicho que la universidad enfrenta dos principales retos: incrementar la calidad de la enseñanza, desarrollar el posgrado brindando más atención al estudiante, y ser una proveedora eficaz del servicio a la sociedad... En ese contexto la universidad debe recuperar su papel de orientadora, iluminadora y provocadora de los cambios estructurales...debe recuperar, desde su posición independiente y con su gran bagaje científico y cultural, su capacidad de iniciativa y crear pautas de pensamiento y de desarrollo científico y técnico que influyan decididamente en la nueva sociedad del siglo XXI. Y todo ello, debe tener lugar en medio de los tres grandes desafíos de la educación superior del siglo XXI (Salmi, 2000): La globalización económica, la creciente importancia del conocimiento y la revolución de la comunicación y la información.

Los últimos cuarenta años han significado un cambio profundo, drástico y no exento de grandes dolores para las universidades chilenas. Para Chile queda como un resultado positivo la enorme expansión de la cobertura, pero envolviendo el costo de una gran pérdida en la profundidad del sistema. Los mecanismos para brindar autonomía a nuevas universidades, junto al abandono de las instituciones tradicionales, brindaron un cuadro mixto en que el problema de calidad es ahora transversal y ha llegado a ser un elemento vital para juzgar objetivamente el desempeño del sistema. Por su parte, la educación media siguió sufriendo notorios problemas de calidad, que ha hecho más difícil combinar la adecuada selección con criterios de equidad. Asimismo, esta situación ha obligado a las universidades más selectivas a implementar programas remediales y de recuperación, para así asegurar mejores condiciones de egreso, pero al mismo tiempo haciendo más larga la estadía esperada de un estudiante. El financiamiento de la investigación siguió siendo un Talón de Aquiles, junto con la competencia investigación-docencia que inducían las políticas públicas de financiamiento de la primera. Las universidades públicas fueron desarticuladas, las universidades regionales no apoyadas en forma significativa, y solo prevaleció un discurso superficial que llamaba a la mayor competencia, cuando las universidades del Estado eran desventajadas desde el mismo Estado.

\section{Nota:}

${ }^{1}$ Este trabajo fue presentado en la Reunión organizada por El Consejo Nacional de Educación del Ministerio de Educación del Perú ¿Hacia 
Dónde va la Universidad Latinoamericana? (Julio de 2016), y se benefició de los comentarios de Manuel Burga, ex Rector de la Universidad de San Marcos (Perú), de Adnei Melges de Andrade, ex Vicerrector de la Universidad de Sao Paulo (Brasil) y de Juan Ramón de la Fuente, ex Rector de la Universidad Nacional Autónoma de México. $\mathrm{El}$ autor agradece la asistencia de Mauricio Cornejo.

\section{REFERENCIAS BIBLIOGRÁFICAS}

Bello, A., 1842

Cifuentes, S., 1997

De Luxán, J. M., 1998

Didriksson, A., 2000

Ferro, J., 1996

López, F., 2011

Millas, J., 1976
Discurso Inaugural de la

Universidad de Chile, Santiago de Chile.

La Reforma Universitaria en Chile (1967-1973), Editorial Universidad de Santiago, Santiago de Chile.

La Misión de la Universidad en Política y Reforma Universitaria, de Luxan Ed., Centro de Estudios de Derecho, Economía y Ciencias Sociales, Editorial S.L., Barcelona.

La Universidad pública en la encrucijada, Educación Superior y Sociedad, Vol. 11 n$^{\circ} 1$ y 2, IESALCUNESCO, Caracas.

Visión de la Universidad ante el siglo XXI. Ediciones Uninorte, Colombia.

Globalización y Educación Superior en América latina y el Caribe. IESALC - UNESCO, Colección Respuestas, Caracas.

En defensa de la Universidad, Artículo del diario El Mercurio, 3 de Enero. 
Millas, J., 1981

Millas, J., 1985

Ortega y Gasset, J., 1927 Responsabilidad de la inteligencia.

Ortega y Gasset, J., 1992 Misión de la Universidad. Alianza,

Quintanilla, A., 1998

Riveros, L., 2008

Riveros, L., 1997

Riveros, L., 2005

Riveros, Luis, 2005 Madrid, 1 ${ }^{\text {a }}$ Reimpresión, 1992.

Idea y defensa de la Universidad, Corporación de Promoción Universitaria, Editorial del Pacífico

Misión de la Universidad frente a las ciencias y las artes en Informaciones Universitarias (25), Diciembre.

Nuevas ideas para la Universidad en Política y Reforma Universitaria, de Luxan Ed., Centro de Estudios de Derecho, Economía y Ciencias Sociales, Editorial S.L., Barcelona.

Financiamiento de la Educación Superior en América Latina: Retos y Dilemas en Tendencias, Fundación CYD, Barcelona - España, Diciembre.

La Universidad de Chile hacia el 2010. Estrategias y acción para un desarrollo sostenible. Santiago, Facultad de Ciencias Económicas y administrativas.

Jorge Millas y su defensa de la Universidad, Revista de Ciencias Sociales, Universidad de Valparaíso, Facultad de Derecho y Ciencias Sociales (49/50), Valparaíso.

La Universidad en el siglo XXI Revista Chilena de Administración Pública, Vol. II (6; 7-20), Santiago de Chile. 
Saavedra, D., 1999

Salmi, J., 2000

Tünnermann, C., 1999

UNESCO, 1998

Van Ginkel, H., 2011 la sociedad del conocimiento, Revista de Sociología 19 (17-29), Santiago de Chile.

Chile, en Historia de las Universidades en América Latina, Unión de Universidades de América latina, Colección UDUAL, Ciudad de México.

Facing the challenges of the TwentyFirst Century, en International Higher Education, (19).

La declaración mundial sobre la educación superior en el siglo XXI. Una lectura desde América latina y El Caribe, Educación Superior y Sociedad, vol. $10 \mathrm{n}^{\circ} 1$, IESALC UNESCO, Caracas.

Declaración Mundial sobre la Educación Superior en el Siglo XXI. Conferencia Mundial sobre la Educación Superior, Paris.

Keynote Address for the Conference of Magna Charta Observatory (September 2011), Contemporary Threats and Opportunities; Academic Freedom and Institutional Autonomy within the context of Accreditation, Quality Assurance and Rankings, Bolonia University Press.

(nd)

Villapalos, G., 1998 